\title{
O PAPEL DA NOÇÃO DE REPRESENTAÇÃO NA CONCEPÇÃO DE CIÊNCIA DE HEINRICH HERTZ'
}

The role of the notion of representation in the science conception of Heinrich Hertz

El papel del concepto de representación en la concepción de la ciencia de Heinrich Hertz

Eduardo Simões ${ }^{2}$ Universidade Federal do Tocantins, Palmas, TO, Brasil.

\section{Resumo}

A obra Eletric Waves (1893) foi o ponto de partida para a análise filosófico-metodológica das teorias científicas por parte de $\mathrm{H}$. Hertz e a culminância dessa prática deu-se com a sua obra póstuma The Principles of Mechanics (1894). Nas introduções a essas duas obras um tema metacientífico se apresenta como núcleo central. Nelas Hertz trata das diferentes representações, imagens ou modelos (esquemas conscientemente construídos) dos fenômenos físicos: no caso da primeira obra, dos fenômenos eletromagnéticos; no caso da segunda, dos fenômenos mecânicos. E a questão que

\footnotetext{
1 Este texto é parte de um estudo mais amplo a respeito das possíveis influências do pensamento de H. Hertz sobre o Tractatus de L. Wittgenstein defendido em 2012 na modalidade de doutorado.

2 Doutor em Filosofia pela Universidade Federal de São Carlos e professor Lógica e Epistemologia do curso de Filosofia da Universidade Federal do Tocantins. Palmas, TO, Brasil. http://orcid. org/0000-0001-7375-8574. E-mail: eduardosimoes@uft.edu.br
} 
tenta resolver é a seguinte: qual é a origem da pluralidade de imagens nas teorias científicas? Seria ela inevitável? É sobre esse tipo de questões que se fixa o presente trabalho na intenção de apresentar o papel da noção de representação na concepção de ciência de Heinrich Hertz.

Palavras-chave: Filosofia. Ciência. Teoria. Representação. Mecânica.

\begin{abstract}
The book Eletric Waves (1893) was the starting point for the philosophical-methodological analysis of scientific theories by $\mathrm{H}$. Hertz and the culmination of this practice was with his posthumous work The Principles of Mechanics (1894). In the introductions to these two books, a meta-scientific theme presents itself as the central nucleus. In these works, Hertz treats of the different representations, images or models (consciously constructed schemes) of the physical phenomena: in the case of the first book, of the electromagnetic phenomena; in the case of the second one, mechanical phenomena. In addition, the question tries to solve is the following: what is the origin of the plurality of images in the scientific theories? Was it inevitable? It is on this type of issues that the present work is fixed in the intention of presenting the role of the notion of representation in the science conception of Heinrich Hertz.
\end{abstract}

Keywords: Philosophy. Science. Theory. Representation. Mechanics.

\title{
Resumen
}

La obra Eletric Waves (1893) fue el punto de partida para el análisis filosófico-metodológico de las teorías científicas por $\mathrm{H}$. Hertz y la culminación de esta práctica se dió con su obra póstuma The Principles of Mechanics (1894). En las introducciones a estas dos obras un tema meta científico se presenta como núcleo central. En ellas Hertz trata sobre las diferentes representaciones, imágenes o modelos (esquemas que se conscientemente construidos) de los fenómenos físicos: en el caso de la primera obra, fenómenos electromagnéticos; en el caso de la segunda, los fenómenos mecânicos. Y la pregunta que trata de resolver es la siguiente: ¿Cuál es el origen de la pluralidad de imágenes en las teorías científicas? ¿Seria inevitable? Es en este tipo de cuestiones que se fija en el presente trabajo con el fin de presentar el papel del concepto de representación en el diseño de la ciencia de Heinrich Hertz.

Palabras clave: Filosofía. Ciencia. Teoría. Representación. Mecánica. 


\section{Introdução}

Em Electric Waves o foco da análise metacientífica de teorias por parte de Hertz se dá sobre os diferentes conjuntos de equações utilizadas por Maxwell para expressar a sua teoria eletromagnética. Hertz entende que no Treatise on Electricity and Magnetism (1873), Maxwell oscila entre diferentes modos de representação de sua teoria, o que explicaria inconsistências em seu interior, favorecendo a introdução de "ideias supérfluas e rudimentares". É o caso do conceito de eletricidade, "Hertz considerava ser impossível dar uma significação única ao termo 'eletricidade' como ele é empregado por Maxwell [...]. Convivem lado a lado na teoria duas concepções incompatíveis entre 'eletricidade' e 'polarização'" (ABRANTES, 1992, p. 356).

Tentando determinar a natureza precisa da teoria de Maxwell através da análise do conjunto de equações que expressavam a sua teoria e, com isso, discernir sobre o que Maxwell estava tratando acerca da natureza dos fenômenos eletromagnéticos, Hertz conclui que Maxwell não dizia nada acerca da natureza física desses fenômenos. A sua teoria, "muito abstrata e sem colorido", resume-se em equações que eram fórmulas lógicas que o habilitavam a lidar com os fenômenos e a entender como eles funcionavam. Daí, Hertz chega à conclusão sobre a teoria de Maxwell:

À questão, “O que é a teoria de Maxwell?" Eu não conheço uma resposta mais direta ou definitiva do que a seguinte: - a teoria de Maxwell é o sistema de equações de Maxwell. Toda teoria que conduza ao mesmo sistema de equações, e, portanto, abranja os mesmos fenômenos, eu consideraria uma forma ou um caso especial da teoria de Maxwell (...). Assim, neste sentido, e apenas neste sentido, podem as duas dissertações teóricas tratadas no presente livro ser consideradas como representações da teoria de Maxwell. Em nenhum sentido elas podem ter a pretensão de serem consideradas traduções precisas das ideias de Maxwell. Ao contrário, é duvidoso que Maxwell, enquanto vivo, as reconheceria como representan- 
tes de seus próprios pontos de vista em qualquer aspecto (HERTZ, 1956 apud COHEN, 1956, grifos nossos).

Hertz propõe, então, a reconstrução axiomática da teoria de Maxwell reduzindo as suas equações a apenas quatro ${ }^{3}$, adotando-as em um sistema dedutivo, onde as mesmas são apresentadas como "relações entre magnitudes físicas que são efetivamente observadas, e não entre magnitudes que servem somente ao cálculo" (HERTZ, 1962, p. 196). Isso resolveria um problema prático, ao invés de somente fornecer um quadro de referência matemático para tratar de problemas da física, dotando-a de uma estrutura lógica. Hertz reconhece que "não é agradável ver equações apresentadas como resultados diretos da observação, onde estávamos acostumados a ver longas deduções como provas aparentes delas". Mas reconhece que esse é o preço que se paga por confundir "a figura simples e familiar apresentada pela natureza, com os trajes vistosos com que nos habituamos a vesti-la" (HERTZ, 1962, p. 28).

Segundo Abrantes (1992, p. 356), em Electric Waves já se encontram definidas as posições metodológicas de Hertz, bem como a sua concepção da tarefa da filosofia da ciência, a saber:

1. A tese de que nossas "ideias físicas e matemáticas" constituem "modos de representação" dos fenômenos (que subdeterminam tais modos de representação).

2. Importância do critério lógico (consistência) na aceitabilidade da teoria científica.

3. A exigência de parcimônia no emprego de hipóteses nas teorias científicas.

\footnotetext{
3 Redução que ocorreu definitivamente com Oliver Heaviside, físico inglês que trabalhou nos desenvolvimentos posteriores da teoria de Maxwell, criando o formalismo matemático que permite que tais equações sejam escritas na forma sintética, como são conhecidas hoje.
} 
Resta-nos saber qual seria a inspiração filosófica de Hertz para a construção de sua filosofia da ciência.

Tanto Janik e Toulmin (1991), quanto Videira (1995), como Carvalho (2007) tratam desse assunto. Segundo Videira (1995, p. 11), tanto Helmholtz quanto Hertz foram inspirados em uma linha de pensamento epistemológico derivado do pensamento crítico de Kant ${ }^{4}$. No caso de Hertz, como se deu essa inspiração? Como aluno de Helmholtz e influenciado pelo mesmo, uma virtude de suas análises era mostrar como o âmbito de qualquer representação poderia ser demonstrado de dentro para fora. Esse procedimento mostra-se kantiano, na medida em que, no programa crítico de Kant sua intenção era mapear a extensão das fronteiras da razão, mostrando-a desde o interior, de uma forma que evitasse toda a dependência de pressupostos metafísicos externos.

Neste sentido, podemos legitimamente falar da atitude de Hertz em relação à teoria física kantiana; como tal, tem um lugar certo ao lado das outras tentativas que já observamos para definir a amplitude, as condições de validade e as fronteiras de diferentes veículos, simbolismos, modos de expressões e/ou linguagens, que eram uma característica dominante do debate intelectual vienense de 1890 em diante (JANIK; TOULMIN, 1991, p. 163).

Mas, alguém poderia objetar que o fato de assim pensar alguns estudiosos, não nos autoriza classificar a postura de Hertz como a de um kantiano. Como resposta, podemos buscar no pensamento do próprio Hertz afirmações que legitimem a sua filiação; a de maior impacto e que ao mesmo tempo encerra essa questão é a afirmação de que "o assunto do primeiro livro é completamente independente da experiência. Todas as asserções feitas são julgamentos a priori no sentido de Kant" (HERTZ,

4 Para Carvalho (2007, p. 58), "Helmholtz relaciona-se diretamente com a sua opção de adotar as formas a priori de Kant como ferramenta de análise dos problemas que vinham se apresentando nos domínios da física na segunda metade do século XIX" e Hertz inspira-se nele. 
1956, p. 45). Mas, em que sentido a filosofia da ciência de Hertz é tributária do pensamento de Kant? É justamente sob o viés do conceito de representação que deve ser entendida a filosofia da ciência de Hertz como tributária do pensamento de Kant.

\section{II}

Quanto à noção de representação no pensamento hertziano vemos que ela é fruto de um momento histórico bastante importante no campo da ciência. No século XIX desenvolveu-se um grande debate sobre a validade do conhecimento científico e suas várias formas de "representação". Esse debate envolveu nomes de grandes cientistas e filósofos alemães como G. Kirchhoff, H. Helmholtz, E. Mach, Hertz e L. Boltzmann.

Sabe-se que o termo representação havia sido colocado em circulação, principalmente, pela filosofia de Kant e que nos cem anos seguintes à publicação da Crítica da Razão Pura (1781), as implicações do programa crítico kantiano, passaram a dominar tanto a filosofia quanto as ciências naturais alemãs. Segundo Janik e Toulmin (1991, p. 133-134), antes de Kant, os elementos substanciais de qualquer teoria do conhecimento eram "percepção sensorial" e "pensamento" (considerados elementos prévios e independentes da experiência), com a "linguagem" (elemento secundário) como instrumento de publicidade para o conhecimento adquirido. Com Kant, primeiramente, as formas linguísticas ou lógicas deixam de ser "elemento secundário" e passam ser qualificadas como uma "experiência" genuína de conhecimento; em segundo lugar, Kant concebe que o conhecimento envolve não apenas interpretação de impressões sensoriais e que essas experiências sensoriais se apresentam com uma estrutura epistêmica. Essa estrutura só pode ser caracterizada em termos das "formas de julgamento" que se expressam na gramática lógica.

Assim, em vez de iniciarmos nossa análise filosófica do conhecimento com as impressões sensoriais não processadas, devemos agora tratar os dados básicos da experiência 
como incluindo 'representações' sensoriais estruturadas, ou Vorstellungen. (JANIK; TOULMIN,1991, p. 134)

Vorstellungen, enquanto significando representação, no sentido kantiano ainda está ligado ao uso "sensorial" e "perceptivo" ("representações sensoriais estruturadas") o que, como vimos, não é o caso da representação no sentido hertziano. Hertz utiliza-se do termo Darstellung para qualificar uma representação científica enquanto tal, por exemplo, a representação gráfica tal como utilizada atualmente em física. Outro termo utilizado por Hertz é o termo Bild, que significa literalmente em alemão "quadro" ou “imagem”. Qualquer equívoco na interpretação desses termos, quando aparecem na filosofia da ciência de Hertz, pode implicar na perversão dessa mesma teoria - o que não é difícil de ser encontrado. Esse é o caso da confusão envolvendo a palavra Bild, promovida por Ernest Mach (1960, p. 318), diz: "Hertz utiliza o termo Bild (image ou Picture) no sentido do antigo uso de ideia pela tradição filosófica inglesa, e aplica-o a sistemas de ideias ou conceitos relacionados a quaisquer domínios". Ao interpretar a palavra Bild como Vorstellungen, isto é, como equivalente ao termo lockiano "ideia" (sensação, percepção), Mach não percebeu que por imagem ou quadro, Hertz não queria denotar ideia, no sentido do empirismo britânico. Hertz estava descrevendo suas Bilder como representações, modelos, esquemas cognitivos. Pelo menos é isso que se entende quando ele trata dos mesmos conceitos na Introdução ao Principles (1956, p. 2):

São possíveis várias imagens (ou modelos) dos mesmos objetos, e essas imagens podem diferir em vários aspectos. Devemos assinalar imediatamente como inadmissíveis todas as imagens que implicitamente contradizem as leis do nosso pensamento. Por conseguinte, postulamos que, em primeiro lugar, todas as nossas imagens serão logicamente permissíveis - ou, sucintamente, que elas serão permissíveis. Distinguiremos como incorretas quaisquer imagens permissíveis se as suas relações essenciais contradizem as 
relações com as coisas externas, isto é, se não satisfazem o nosso primeiro e fundamental requisito. Daí postulamos, em segundo lugar, que as nossas imagens sejam corretas. Mas duas imagens permissíveis e corretas dos mesmos objetos externos podem ainda diferir no tocante à adequação. De duas imagens do mesmo objeto, a mais adequada, mais apropriada, é aquela que inclui o maior número de relações essenciais do objeto - a imagem que podemos chamar a mais distinta. De duas imagens de igual distinção, a mais apropriada é aquela que contém, além das características essenciais, o menor número de relações supérfluas ou vazias - a mais simples das duas. As relações vazias não podem ser inteiramente evitadas; entram nas imagens porque são simplesmente imagens - imagens produzidas por nossa mente e necessariamente afetadas pelas características de seu modo de representação (portrayal) (HERTZ, 1956, p. 2, grifos nossos).

Essas imagens que são "produzidas por nossa mente", devem respeitar os critérios que permitem avaliar criticamente toda e qualquer teoria científica: permissibilidade (Zulässigkeit) lógica, correção (Richtigkeit) e adequação (Zwegmässigkeit) (HERTZ, 1956, p. 2). A permissibilidade é o requisito de consistência lógica que tem de ser cumprido por qualquer teoria: as imagens não podem contrariar as "leis do nosso pensamento", isto é, não podem ser logicamente contraditórias. A correção, por outro lado, atua como requisito de que haja correção empírica: qualquer teoria proposta tem de ser compatível com os dados da experiência - as imagens devem satisfazer à exigência de conformidade com os fatos. Por fim, a adequação, que tem a ver com a forma exterior da teoria, com a clareza e simplicidade dos conceitos e leis utilizados - além de serem claras na expressão dos traços principais dos fenômenos, não se devem incluir elementos supérfluos nas teorias. Se duas teorias são permissíveis e corretas empiricamente, então, pode-se ainda escolher entre elas olhando para a simplicidade e elegância dos seus conceitos e leis fundamentais. Contudo, 
a noção de simplicidade hertziana não é primordialmente estética, de gosto, mas lógica. Devem ser descartadas proposições ou suposições cuja exclusão em nada reduz o poder preditivo da mesma teoria.

É importante notar que Hertz é herdeiro da tradição dos físicos alemães que tinha como prática uma abordagem formalista dos fenômenos naturais. Segundo essa abordagem, as teorias matemáticas objetivavam-se por articular a experiência através de equações diferenciais, sem fazer uso de hipóteses. "Tal postura contrastava com a necessidade que sentiam os físicos britânicos de visualizarem fisicamente o formalismo [...]" (ABRANTES, 1992, p. 3). O formalismo, no entanto, não erradica todos os problemas, que sejam da eletrodinâmica ou da mecânica. Hertz admite que ele não é capaz de se eximir da obscuridade de conceitos, como das relações vazias; e o entendimento e resolução desses dar-se-á com The Principles of Mechanics.

\section{III}

Em Principles, por exemplo, com relação ao formalismo subjacente às concepções de éter (introduzido nas teorias de Descartes, Newton, Maxwell), Hertz diz que "é prematuro, por exemplo, basear as equações do movimento do éter nas leis da mecânica até que tenhamos obtido um acordo perfeito sobre o que se entende por esse nome" (HERTZ, 1956, Prefácio). E que, mesmo sendo a teoria subdeterminada pela experiência, isto é, mesmo participando por meio do pensamento na construção teórica, as representações, por serem produtos de nossas mentes, não podem evitar que sejam nelas introduzidas, por conveniência nossa, relações vazias. Relações vazias seriam, por exemplo, a introdução de termos obscuros e de ideias supérfluas e rudimentares e que não estão, portanto, diretamente vinculados à experiência (HERTZ, 1956, p. 7). E esse é o caso de conceitos como energia e força; com relação à força diz Hertz que "mesmo que as forças tenham sido apenas introduzidas por nós na natureza, não devemos, por isso, considerar sua introdução como inadequada. Estamos convenci- 
dos, desde o princípio, de que relações supérfluas (ou vazias) não podem ser totalmente evitadas em nossas imagens" (HERTZ, 1956, p. 12). E isso é justificável na medida em que há uma "tendência inata da razão para passar da própria experiência sensível para uma explicação dessa experiência, embora tal explicação se situe para além dela, na esfera das 'coisas em si mesmas'” (KANT, 1787 apud JANIK; TOULMIN, 1991, p. 164). Aqui, mais uma vez, a filiação kantiana de Hertz torna-se evidente.

Com relação à estrutura de uma teoria científica, e na contramão de tudo o que se espera de tais teorias, Hertz inova quando propõe o que ele chama de The Principles of Mechanics: trata-se de um montante de proposições "que satisfazem a exigência de que o conjunto da mecânica possa ser desenvolvido a partir delas através de raciocínio puramente dedutivo, sem qualquer apelo adicional à experiência" (HERTZ, 1956, p. 4). É justamente essa postura que caracteriza a epistemologia de Hertz, portanto, sua filosofia da ciência. Para ele, uma representação científica, a par das exigências de que sua origem seja os dados empíricos e devendo com eles concordar, pode ser permissível, correta e adequada, mesmo sem fazer um apelo direto à experiência, mesmo porque, "aquilo que é derivado da experiência pode novamente ser anulado pela experiência" (HERTZ, 1956, p. 9). É daí que se levanta a questão da subdeterminação da teoria pela experiência. Se para Hertz a teoria é subdeterminada pela experiência, isso significa que suas concepções se afastam da dos físicos fenomenistas, para os quais "todo conceito empregado em uma teoria física deve, em última instância, encontrar sua relação concreta na intuição empírica" (CASSIRER, 1979, p. 128).

Cassirer considera que a epistemologia de Hertz constituiu um desvio importante no desenvolvimento das imagens de conhecimento ligadas ao desenvolvimento da física matemática do século XIX defendendo um método hipotético-dedutivo que pressupunha a liberdade da atividade teórica.

A admissão da subdeterminação das imagens pelos dados empíricos permite a introdução de 'um novo elemento de liberdade na escolha de conceitos teóricos' representado pela possibilidade de inclusão de 'conceitos que não correspondem 
a percepções', como, por exemplo, as massas ocultas hipotéticas presentes na representação hertziana da mecânica. Os limites dessa liberdade teórica, assim como os da representação científica como um todo, são determinados pelos critérios estabelecidos por Hertz (CARVALHO, 2007, p. 67).

E desses critérios é importante dar uma atenção especial para o da adequação. Esse critério, que não precede os demais, torna-se imprescindível visto ser ele quem garante a simplicidade da imagem, na medida em que propõe que ela seja despida dos seus "trajes vistosos" (HERTZ, 1960, p. 28). Ou então, que sejam reduzidas ao máximo as concepções arbitrárias nelas introduzidas como consequência pela qual nossas mentes as representam. Simplicidade é a palavra de ordem; mas o que definiria uma imagem como simples? Simples para quem?

Todos os físicos concordam que o problema da física consiste em remeter os fenômenos da natureza às leis simples da mecânica. Mas não há o mesmo acordo sobre o que são estas leis simples. Para a maioria dos físicos, elas são simplesmente as leis do movimento de Newton. Mas, na realidade, estas leis obtêm sua significação interna e seu significado físico através do pressuposto tácito de que as forças a que elas se referem são de natureza simples e possuem propriedades simples. Mas, a este respeito, não temos certeza do que é simples e permissível e do que não o é: é aqui que não mais encontramos qualquer acordo geral. Assim, surgem diferenças reais de opinião sobre se esse ou aquele pressuposto estão ou não de acordo com o sistema usual da mecânica. É no tratamento de novos problemas que reconhecemos a existência de tais questões em aberto como um obstáculo real ao progresso (HERTZ, 1956, Prefácio).

Outra questão se coloca: se a adequação é garantida pela simplicidade de uma imagem (quando mais simples mais adequada ela é), a relação 
inversa teria o mesmo valor? Nem sempre a adequação é garantida pela simplicidade: uma imagem adequada é antes de tudo "aquela que descreve mais relações essenciais do objeto" (HERTZ, 1956, p. 2). No entanto, não podemos decidir sem ambiguidade se uma imagem é mais adequada ou não; quanto a isso, surgem diferenças de opinião. “Uma imagem pode ser mais adequada para um determinado propósito, outra para outro propósito; somente testando gradualmente muitas imagens é que podemos, finalmente, ter sucesso na obtenção da mais apropriada" (HERTZ, 1956, p. 3). Vê-se, com isso, que Hertz está falando de "teste de imagens". Se se trata de testar imagens é mais do que lícito que tais imagens sejam entendidas como Darstellung, isto é, como uma representação científica aos moldes da representação gráfica tal como utilizada em física. Além do mais, se "uma imagem pode ser mais adequada para um determinado propósito, outra para outro propósito [...]", Hertz admite a necessidade de uma pluralidade de representações para o desenvolvimento da ciência - "Hertz atribui à retórica subjacente aos modelos físicos construídos na elaboração de uma representação um importante papel na comunicação entre os cientistas" (JANIK, 2002, p. 8). Mas, então, o que dizer das críticas de Hertz aos "conceitos obscuros" tanto na teoria eletromagnética, quanto na mecânica newtoniana que envolve as noções de energia e força? E porque querer eliminá-los? Sua objeção a tais conceitos envolve uma importante extensão do critério de permissibilidade lógica, segundo o qual, na introdução de elementos em uma teoria, tais elementos não poderiam ser contraditórios ou ocasionar problemas de interpretação promovidos pela sua característica de obscuridade.

Para que uma imagem de certas coisas externas possa, em nosso entendimento, ser permissível, não basta que suas características sejam consistentes entre si, mas elas não devem contradizer as características de outras imagens já estabelecidas em nosso conhecimento (HERTZ, 1956, p. 23). 
E para resolver o problema gerado pela introdução de elementos obscuros em uma imagem, a solução assumida por Hertz é a de criar "modelos alternativos que renunciem às características não essenciais que incluímos nestes modelos e que se tornaram embaraçosas para nós" (JANIK, 2002, p. 9).

O modo pelo qual Hertz lida com os problemas metafísicos que surgem no curso do desenvolvimento de uma teoria científica exige, literalmente, uma representação (matemática) de nossas teorias, de maneira a sermos capazes de distinguir, rigorosamente, aqueles elementos no modelo (Bild) que derivam da necessidade lógica e aqueles que se referem à evidência empírica, daqueles que nele inserimos arbitrariamente com vistas à efetividade retórica. Na verdade, a ênfase de Hertz em purgar nossos modelos de inconsistência assemelha-se muito à análise lógica (i. e., a componente matemática na elaboração de modelos) (JANIK, 2002, p. 9).

E isso é endossado pelo próprio Hertz quando fala de sua metodologia de trabalho ao tratar da diversidade de imagens autocontraditórias e de elementos obscuros as quais tentava depurar:

Como forma de dar expressão ao meu desejo de provar a pureza lógica do sistema em todos os seus detalhes, eu moldei a representação na velha forma sintética. Por isso, a forma utilizada tem o mérito de nos compelir a especificar, de antemão, definitivamente, mesmo que monotonamente, 0 valor lógico que se pretende dar a todo enunciado importante. Isto torna impossível a utilização das reservas e ambiguidades convenientes para as quais somos atraídos pela riqueza de combinações do discurso ordinário (HERTZ, 1956, p. 35).

Assim, a aplicação da "velha forma sintética", que era predominantemente matemática, possibilitava comunicar fatos do mundo, na forma de uma Bild matemática. A univocidade dessa linguagem e a sua 
consequente capacidade de manter-se livre das ambiguidades, eram resultado direto de sua estrutura matemática, de sua forma. Forma que não resulta da experiência, nem de quaisquer convenções ou definições arbitrárias. Pelo contrário, era imposta à experiência de tal maneira que Ihe incutia uma ordem de natureza econômica (subdeterminação). Hertz pode, então, transformar a crítica da mecânica, colocando-a em uma base filosoficamente segura ao considerar sua estrutura matemática e não o desenvolvimento histórico e psicológico dos seus conceitos. E ele consegue fazer isso justamente ao demonstrar que a teoria clássica da mecânica newtoniana e do energetismo de Maxwell poderiam formar um sistema matemático de axiomas e deduções e descrever o mundo real da natureza em contraste com os mundos logicamente concebíveis 5 . Se distinguirmos entre os passos pelos quais tal cálculo matemático é articulado e os passos empíricos ou pragmáticos pelos quais o resultante sistema de axiomas é aplicado na experiência real, a questão colocada na nota de rodapé número 5 responder-se-á por si mesma.

\section{IV}

Certo é que, segundo a convicção de Hertz, a sua proposta filosófico-metodológica resistiu aos critérios estabelecidos por ele mesmo. Quanto à permissibilidade lógica, sua teoria "não teria" introduzido elementos obscuros e nem promovia contradições com as imagens já estabelecidas em nosso conhecimento ${ }^{6}$. Ao contrário, promovia uma coerência entre seus conceitos e princípios fundamentais, assim como, com os limites

\footnotetext{
5 Essa afirmação custa caro ao sistema de Hertz, visto que a questão que dela se ascende é: e o próprio sistema hertziano trata do mundo real ou de um mundo logicamente concebido? Pelo menos, no que tange à crença do próprio Hertz, ele estava tratando do mundo real (mesmo introduzindo a ideia de massas ocultas e estando compromissado com o programa do éter).

6 No caso das massas ocultas, estas representam uma exigência metodológica importante em seu sistema e não se trata de uma tese ontológica. "A razão da complicação é perfeitamente óbvia. A perda de simplicidade não se deve à natureza, mas ao nosso conhecimento imperfeito da natureza" (HERTZ, 1956, p. 39). Hertz promove, então, uma distinção entre teses ontológicas (de que há "desígnios na natureza" assim como pensava Aristóteles) e exigências metodológicas.
} 
de sua aplicabilidade. Tratava-se de uma proposta cujos modelos eram frutos da elaboração matemática da teoria, cuja função heurística desempenhada era a de facilitar sua generalização, dando-Ihe um caráter de independência formal. Com relação à correção, a despeito de tudo o que se tem dito sobre o seu caráter eminentemente dedutivo, vemos que não é bem assim: Hertz não despreza a importância da experiência, tanto é que se o livro I baseia-se "nas leis de nossa intuição interna", o livro II trata dos "símbolos de objetos de nossa experiência externa". A representação mecânica de Hertz pressupõe um isomorfismo entre pensamento e natureza, isomorfismo esse, que é garantido pela Lei Fundamental assim enunciada: "todo sistema livre persiste em seu estado de repouso ou de movimento uniforme na trajetória a mais retilínea" (HERTZ, 1956, p. 144)7. Mesmo assim, salienta Hertz, "não temos que temer a objeção de que, ao construir uma ciência dependente da experiência, tenhamos extrapolado o mundo da experiência" (HERTZ, 1956, p. 30).

O neo-kantismo de Hertz o faz, efetivamente, acreditar num isomorfismo entre a sequência de nossos pensamentos e a sequência de eventos no mundo. A importância que atribui às dimensões da teoria científica que não se reduzem à experiência, mas correspondem à atividade de uma autêntica 'imaginação científica', é dificilmente compatível com formas ingênuas de empirismo (ABRANTES, 1992, p. 357).

É o caso, por exemplo, da postulação das conexões geométricas entre massas: onde encontrar na natureza essas conexões? Como testá-las empiricamente se até a "massa tangível", tratada como símbolo de objetos de nossa experiência pelo livro II, ao final, acaba por fazer uma remissão

No caso das massas ocultas, estas representam uma exigência metodológica importante em seu sistema e não se trata de uma tese ontológica, segundo Hertz.

7 Trata-se de um princípio variacional local, ao contrário do princípio de Hamilton que possui um caráter global, mas cuja explicação é geral, aplicando-se, evidentemente, a qualquer outra representação caracterizada por um conjunto de princípios ou leis fundamentais. 
à massa, "enquanto intuição interna", tal como definida pelo livro I? Eis, por exemplo, o conceito de massa no livro II:

$\S$ 300. Regra 3. A massa dos corpos que podemos tocar é determinada por pesagem. A unidade de massa é a massa de algum corpo estabelecida por convenção arbitrária.

A massa de um corpo tangível, como determinado por esta regra, possui a propriedades atribuídas à massa idealmente definida ( $(4)$. Ou seja, ela pode ser concebida como dividida em um número qualquer de partes iguais, sendo cada uma delas indestrutível e imutável e capaz de ser empregada como marca de referência, sem ambiguidade, de um ponto no espaço em um certo instante para outro ponto no espaço em qualquer outro instante ( $\$ 3$ ). A regra é, além disso, determinada e única quando se considera corpos tangíveis, apesar das incertezas que não podemos eliminar de nossa experiência real passada ou futura (HERTZ, 1956, p. 140-141).

Essas massas relacionar-se-iam por vínculos geométricos nos sistemas naturais. Elas e seus vínculos no sistema mecânico hertziano dispensariam a utilização dos conceitos obscuros de força e energia. Isso porque, seria racionalmente concebida a visualização dessas relações geométricas, enquanto consequências necessárias das mudanças de posição dessas massas - em detrimento da ideia de força ou energia. Mas, mesmo cumprindo com o critério de permissibilidade lógica e construindo, portanto, um modelo matemático para a explicação da mecânica, Hertz insiste na necessidade de empregar um elemento ad hoc em sua teoria, dando asas para a livre construção de uma hipótese:

§ 301. Acréscimo a Regra 3. Admitimos o pressuposto que, em adição aos corpos que podemos tocar, existem outros corpos os quais não podem ser tocados, movidos, nem colocados em uma balança, e para os quais a Regra 3 não é aplicável. As massas de tais corpos apenas podem ser determinadas por hipótese. 
Em tal hipótese, temos a liberdade de atribuir a estas massas apenas aquelas propriedades que são consistentes com as propriedades da massa idealmente definida (HERTZ, 1956, p. 141).

Mesmo que tal concepção ainda não fira a permissibilidade de sua teoria (ela não deixa de ser logicamente coerente visto que "tal elemento" se serve ao aspecto retórico), ela incide em uma possível perda de simplicidade dela. Mas, Hertz defende que somente por meio de hipóteses podemos submeter os fenômenos à legalidade. No caso das massas ocultas, por exemplo, a sua função seria a de "predeterminar os movimentos das massas visíveis do sistema, ou as mudanças de suas coordenadas visíveis, não obstante nossa ignorância sobre a posição das massas ocultas" (HERTZ, 1956, p. 224).

Quanto à simplicidade, ainda há um aspecto a ser considerado: qual é o percentual de compromisso de Hertz com o programa do éter? Mesmo tendo afirmado que "é prematuro tentar basear as equações do movimento do éter nas leis da mecânica até que tenhamos obtido um acordo sobre o que se entende por este nome" (HERTZ, 1956, p. 1), sabe-se que ele se insere em uma tradição mecanicista que remonta a Descartes, compromissada com a hipótese de que a ação física se transmite à distância - é o caso da crença de Helmholtz, seu mestre. Em sua época eram comuns os debates acerca da existência ou não de um meio etéreo responsável pela propagação dos fenômenos eletromagnéticos. Hertz poderia muito bem ter sido influenciado pela convicção de Helmholtz de que a ação física se dá à distância, no entanto, seu trabalho como físico experimental o fez aproximar-se da teoria de Maxwell, para qual encontrou aplicação prática. Sabe-se que Maxwell ainda estava compromissado com o programa do éter, mesmo tendo admitido que a ação física se dê de forma contínua e mediatizada; essa era a sua firme convicção com a qual pretendia desenvolver uma teoria completa dos fenômenos eletromagnéticos. Para Hertz, "as forças invariáveis à distância fornecem apenas uma primeira aproximação da verdade [...]. Uma segunda aproximação da verdade pode 
ser alcançada por remeter as supostas ações à distância a movimentos em um meio que tudo permeia e cujas partes menores estão submetidas a conexões rígidas" (HERTZ, 1956, p. 41). É nesse meio etéreo que os estudos em eletromagnetismo tentavam associar as supostas ações à distância ao movimento de minúsculas partículas de éter. E é esse o campo "em que a batalha decisiva entre as diferentes hipóteses fundamentais da mecânica deveria ser travada" (HERTZ, 1956, p. 41). A representação de Hertz, "terceira imagem", oferece uma alternativa para um modelo de éter que guarda as características e os princípios físicos e geométricos do modelo estabelecido para as massas tangíveis - mesmo que isso não seja assumido explicitamente por ele - isso porque, como no exemplo das massas ocultas, é possível predeterminar os movimentos das massas visíveis do sistema, ou as mudanças de suas coordenadas visíveis, não obstante nossa ignorância sobre as posições das massas ocultas.

\section{V}

Diferentemente da representação newtoniana que, segundo Hertz, teria sido "desenvolvida com o propósito de possibilitar a rápida familiarização de aprendizes com o que lhes é requerido na vida diária" (HERTZ, 1956, p. 40), a gramática sistemática, produto de sua representação da mecânica, não é simples ou adequada para os não iniciados, nem apropriada para aplicações práticas ${ }^{8}$. Se não é assim, quais seriam os méritos da proposta hertziana para a mecânica? Se medidos sob a luz de seus próprios critérios para a aplicação em mecânica, chegaremos aos resultados expressos acima - tanto é que praticamente não se discute The

\footnotetext{
8 A pretensão da filosofia da ciência de Hertz era a unificação de várias representações: no campo do eletromagnetismo, partindo da busca do entendimento de como a teoria de Helmholtz havia chegado ao mesmo resultado que a de Maxwell (que sugeria que a ação física se transmitia de forma contígua e mediatizada), mesmo sugerindo o fenômeno das ações à distância, propôs a unificação das representações subjacentes às equações de Maxwell; na mecânica, propôs a unificação das representações newtoniana e energetista.
} 
Principle of Mechanics nas academias. No entanto, o mesmo não pode ser dito em filosofia da ciência.

Os aspectos fundamentais de sua filosofia da ciência exibem-se com maior clareza e coerência quando sua análise se fixa no instrumental kantiano de que Hertz lançou mão. Assim, no sentido de evitar qualquer tipo de interpretação ontológica, Hertz utiliza-se das ideias de imagem e representação (CARVALHO, 2007, p. 79).

Há uma peculiaridade no entendimento da ciência e de seu funcionamento por parte de Hertz. Entendeu que o objetivo de uma teoria científica não era outro que não o de "antecipar eventos futuros" para organizar o nosso presente. Para isso, faz-se necessário a construção de modelos matemáticos de tal modo que as consequências de suas imagens equivalham às imagens das consequências das coisas representadas, isto é, que haja um isomorfismo entre pensamento e natureza. No entanto, é a teoria subdeterminada pela experiência, ou melhor, a teoria antecede-a, isso porque, "criamos imagens da natureza" - mesmo admitindo liberdade de criação, nossas teorias podem sim admitir "relações vazias". Tais relações, muito mais do que teses ontológicas, são exigências metodológicas do sistema. Daí é que se faz necessário que se estabeleçam critérios para avaliar criticamente as teorias científicas como os de permissibilidade, correção e adequação.

$\mathrm{Na}$ elaboração de uma teoria científica, não há nada que impeça que sua estrutura seja concebida sob base dedutiva, isso porque, tais proposições que "apontam" para elementos não empíricos, ainda sim, figuram as consequências necessárias das coisas representadas na natureza - a sequência de nossos pensamentos representa a sequência dos eventos do mundo. Basta que definamos as regras de correspondências e o cálculo que, quando a ele é conferido um conteúdo semântico, serve-se muito bem como um componente a priori de nossas teorias. Ainda assim, Hertz admite que "ideias e concepções que são assemelhadas, porém diferentes, podem ser simbolizadas da mesma maneira nos diferentes modos de 
representação" (HERTZ, 1956, p. 21) e que o conteúdo físico é bastante independente da forma matemática de uma imagem.

Para a construção de imagens, nada nos impede de lançarmos mão do uso de hipóteses, uma vez que, é insuficiente para a busca de uma legalidade universal, considerar somente aquilo que é diretamente observado: "Se nós desejarmos obter uma imagem do universo que seja bem-acabada, completa, e conforme a lei, nós temos que pressupor, por trás das coisas que nós vemos, outras coisas invisíveis - imaginar vínculos escondidos, além dos limites de nossos sentidos" (HERTZ, 1956, p. 25). E isso não significa recorrer à metafísica: "a física (...) não mais reconhece como seu dever ir ao encontro das exigências da metafísica" (HERTZ, 1956, p. 23), pois, como dissemos, trata-se de uma exigência metodológica e não da criação de uma tese ontológica. Pelo menos, não está claro em que ponto, para Hertz, teoria e experiência devem estar obrigatoriamente associadas. Por fim, a par das várias interpretações com respeito ao pensamento e à postura filosófica de Hertz, assumimos a visão de Cohen (1956), para o qual Hertz teria de imbuído da responsabilidade de reconstrução lógica ou racional de todo o sistema da mecânica até então disponível, eximindo dos vários modelos os elementos obscuros que afetavam a sua inteligibilidade. Ainda assim, gostaríamos de acrescentar que, além dessa reconstrução, aos moldes da filosofia da ciência do empirismo lógico, Hertz estava compromissado (pelo seu trabalho como físico experimental) com o programa do éter associado à explicação da ação contígua e mediatizada. Com isso, distanciamos Hertz de qualquer programa ou proposta em física de sua época ou de épocas passadas e o aproximamos da tradição mecanicista de Maxwell, acrescentado a ela a postura neokantiana das formas da intuição sensível, entendendo que, em termos kantianos, "toda a mecânica é representada dentro dos limites do empírico, mas não dentro das fronteiras do empiricamente dado" (JANIK, 2002, p. 21). 


\section{Referências}

ABRANTES, Paulo Cesar Coelho. A filosofia da Ciência de Heinrich Hertz. In: ÉVORA, Fátima Regina Rodrigues (ed.). Século XIX: O Nascimento da Ciência Contemporânea. Campinas: Unicamp, 1992. p. 351-375.

CARVALHO, Marco Antônio A. O Conceito de Representação na Física de Heinrich Hertz: uma Abordagem Histórica. Dissertação (Mestrado em História) - Faculdade de Filosofia e Ciências Humanas, UFMG, Belo Horizonte, 2007.

CASSIRER, Ernest. El Problema del Conocimiento. México: Fondo de Cultura Economica, 1979. v. 4.

COHEN, Robert Stephan. Hertz's philosophy of science: an introductory essay. In: HERTZ, Henrich. The Principles of Mechanics. New York: Dover, 1956.

HERTZ, Henrich. Electric Waves. New York: Dover Publications, 1962.

HERTZ, Henrich. The principles of mechanics: presented in a new form. Preface by Hermann von Helmholtz. Authorized English translation by D. E. Jones and J. T. Walley. With a new introduction by R. S. Cohen. New York: Dover Publication, 1956.

JANIK, A. Wittgenstein, Hertz and Hermeneutics. [New York, NY]: Springer, 2002. (Boston Studies in the Philosophy and History of Science book series - BSPS, v. 225).

JANIK, Allan; TOULMIN, Stephen. A Viena de Wittgenstein. Trad. Álvaro Cabral. Rio de Janeiro: Campus, 1991.

KANT, Immanuel. Crítica da Razão Pura. Trad. Manuela Pinto dos Santos, Alexandre Fradique Morujão. 6. ed. Lisboa: Fundação Calouste Gulbenkian, 2008.

$\mathrm{MACH}$, Ernest. The Science of Mechanics: A Critical and Historical Account of Its Development. Open Court Publishing Company, 1960.

MAXWELL, Jame Clerk. A Treatise on Electricity and Magnetism. Nova York: Oxford University Press, 1998. v. II.

VIDEIRA, Anonio Augusto Passos. A Física entre a Mecânica Clássica e a Filosofia: os exemplos de Helmholtz, Boltzmann e Hertz. Revista da Sociedade Brasileira de História da Ciência, Rio de janeiro, n. 13, p. 11-14, jan./jun. 1995. https://doi.org/10.14195/978-989-26-0764-1 12 
O PAPEL DA NOÇÃO DE REPRESENTAÇÃO NA CONCEPÇÃO | EDUARDO SIMÕES

\section{Endereço postal}

Eduardo Simões

Colegiado de Filosofia. Universidade Federal do Tocantins. Quadra 109 Norte, Av. NS 15, s/n. ALCNO 14, Bloco BALA 2, Sala 16, CEP - 77001-090, Palmas/TO 